\title{
Grammatical and lexical errors of japanese sentence essay of STIKES Medistra Lubuk Pakam nurses as apprentices to Japan
}

\author{
Adriana Hasibuan ${ }^{1 *}$, Rani Arfianty ${ }^{1}$ \\ ${ }^{1}$ Japanese Language Department Faculty of Cultural Science, Universitas Sumatera Utara, \\ Medan, Indonesia \\ *Email: adrianahasibuan00@gmail.com
}

\begin{abstract}
This paper aims to analyze Japanese grammatical and lexical errors in written languages. This study involved 45 nurses from the School of Health Sciences as apprentices to Japan with a 180-word Japanese essay sample based on the Language error definition of Corder (1981) and Weinreich's interference definition (1970). In the process of switching Indonesian into Japanese, errors always occur as they speak. Language learners simply move the grammar rules of Indonesian language into Japanese without thinking about the rules that exist in Japanese. Translating from Indonesian into Japanese, interference is the most powerful factor. When learning Japanese, Indonesian as a mother tongue (B1) is always disruptive, Indonesian language has an influence on grammatical and lexical errors of Japanese written by STIKES nurse of Medistra Lubuk Pakam as apprentices to Japan. Errors made by nurses based on linguistic categories were $33.66 \%$ errors in the morphology field, $23.38 \%$ syntactic errors and $42.96 \%$ errors in the lexical field. Error occurred due to negative transfer.
\end{abstract}

Keyword: error, grammatical, lexical

\section{PENDAHULUAN}

\subsection{Latar Belakang}

Pembelajaran bahasa asing sebagai bahasa kedua bukan lagi satu fenomena baru di Indonesia. Bahasa Jepang sebagai bahasa asing telah diberi perhatian serius oleh pemerintah Indonesia sejak tahun 1958. Pendidikan bahasa Jepang secara de facto dibuka oleh lembaga kebudayaan Jepang di Jakarta bekerjasama dengan mahasiswa Indonesia yang baru kembali belajar dari Jepang. Pada tahun 1980 pendidikan bahasa Jepang mulai berkembang sampai ke wilayah Sumatera. Menurut data the Japan Foundation (2017) ada sebanyak 430 lembaga pendidikan bahasa Jepang tingkat menengah, 80 lembaga pendidikan bahasa Jepang tingkat perguruan tinggi, dan 98 lembaga pendidikan bahasa Jepang di tingkat kursus.

Bahasa Jepang merupakan bahasa asing di Indonesia, dan sudah pasti berbeda dengan bahasa Indonesia. Melalui pembelajaran bahasa Jepang, Indonesia akan menambah pengetahuan tentang budaya Jepang sehingga masayarakat Indonesia mempunyai peluang bekerja di Jepang. Namun begitu, setiap bahasa mempunyai sistem bahasa yang berbeda. Perbedaan ini akan menimbulkan masalah kepada pembelajarannya. Disamping menghasilkan bentuk yang tepat dalam bahasa kedua, pembelajar bahasa Jepang ini juga menghasilkan bentuk yang menyimpang di dalam penggunaan bahasa kedua. Bentuk yang menyimpang tersebut ialah bentuk yang berbeda dengan aturan bahasa kedua dan dikatakan bahwa keadaan ini berlaku sebagai akibat perbedaan wujud antara dua bahasa yang dipelajari.

Fenomena penyimpangan dalam pembelajaran bahasa kedua (B2) dikenali sebagai gangguan (interferensi). Weinreich (1970) menyatakan bahwa interferensi yang merupakan penyimpangan dalam penggunaan bahasa dari norma-norma yang ada sebagai akibat kontak bahasa atau mengenal lebih dari satu bahasa dalam kalangan penuturnya. Belajar B2 bukanlah proses memperoleh bahasa yang baru, melainkan merupakan penambahan belajar sejumlah alternatif baru bagi subset aturan-aturan bahasa yang sudah diketahui, digunakan untuk menghasikan dan memahami ujaran-ujaran. Selanjutnya pemerolehan B2 merupakan proses yang kompleks dalam pembelajaran bahasa setelah B1 (Corder:1973, Ellis: 2015). Apabila unsur B1 sama dengan B2 
disebut transfer positif akan memudahkan pembelajar B2, dan bila unsur B1 berbeda dengan unsur B2 akan menimbulkan transfer negatif (Odlin:1998).

Pemerolehan B2 (bahasa Jepang) sangat kuat dipengaruhi B1(bahasa Indonesia) pada tingkattingkat bahasa, seperti kosa kata maupun tatabahasa. Kesalahan sistematis yang dibuat pembelajar B2 disebabkan pengetahuan sistem B2 berada pada satu titik di tahap bahasa antara (interlanguage), yaitu pada peringkat peralihan dari B1 kepada B2. Interlanguange senantiasa berubah-ubah semasa pemerolehan B2. Pada tahap interlanguage, pembelajar membuat kesalahan karena belum menguasai B2 dengan sempurna dan dipengaruhi B1. Ozeki (2010) menyebutkan terdapat dua jenis kesalahan yang dilakukan oleh pembelajar bahasa Jepang yaitu; 1) kesalahan inter- lingual adalah kesalahan yang disebabkan gangguan dari bahasa ibu (B1) dikarenakan perbedaan diantara kedua bahasa, 2) kesalahan intra-lingual yaitu kesalahan yang terjadi bukan disebabkan pengaruh B1, tetapi kesalahan karena proses pengembangan. Dari sudut linguistik pembelajar bahasa Jepang belum menguasai dengan sempurna sistem linguistik pada peringkat morfologi, sintaksis dan leksikal.

\subsection{Rumusan Masalah}

Proses belajar bahasa selalu terjadi apa yang disebut transfer bahasa, dimana dalam transfer itu pembelajar selalu menerapkan unsur-unsur bahasa ibu (B1) kedalam bahasa target (B2) yang sedang dipelajarinya. Dalam proses ini terjadilah interferensi atau disebut kesalahan berbahasa yang menurut beberapa ahli merupakan peristiwa negatif, dan beberapa ahli lain berpendapat hal ini adalah fenomena yang wajar atau positif. Pengaruh B1 dalam pemerolehan B2, sehingga pembelajar memakai bentuk-bentuk linguistik bahasa Indonesia dan bahasa Jepang secara bergantian. Adanya perbedaan struktur dan bentuk-bentuk linguistik bahasa Jepang dan bahasa Indonesia menjadi hambatan bagi pembelajar dalam menguasai bahasa Jepang yang baik dan benar (Yoshikawa :1997). Untuk itu yang menjadi pertanyaan dalam masalah ini adalah ;

1. Bagaimana bentuk kesalahan gramatikal dan kesalahan leksikal bahasa Jepang yang dibuat perawat STIKES Medistra Lubuk Pakam sebagai peserta magang ke Jepang?

2. Bagaimanakah penyebab kesalahan gramatikal dan kesalahan leksikal bahasa Jepang dalam tulisan perawat STIKES Medistra Lubuk Pakam sebagai peserta magang ke Jepang?

\subsection{Tinjauan Pustaka}

Rani\&Rani (2017) dalam penelitiannya mengenai kesalahan pembentukan kalimat pasif bahasa Jepang, pelajar melakukan kesalahan dalam merubah bentuk verba pasif bahasa Jepang, memilih partikel yang tepat dalam membentuk kalimat pasif bahasa Jepang, kesalahan menyusun subjek dan objek pelaku pada kalimat pasif bahasa Jepang, dan kurangnya pemahaman antara bentuk yari morai bahasa Jepang sehingga pelajar menggunakan kalimat pasif untuk kalimat yang menunjukkan rasa terima kasih.

Hama (2005) menyatakan bahwa pelajar membuat kesalahan ketika membuat karangan bahasa Jepang bukan hanya semata-mata karena gangguan dari B1, tetapi juga disebabkan pengajaran B2 yang kurang sesuai dengan pelajar.

\subsection{Landasan Teori}

Ellis (1984) mengatakan bahwa analisis kesalahan adalah suatu prosedur kerja yang biasanya digunakan oleh para peneliti dan guru bahasa yang meliputi pengumpulan sampel, pengidentifikasian kesalahan yang terdapat dalam sampel, penjelasan kesalahan, pengklasifikasian kesalahan berdasarkan penyebabnya, serta pengevaluasian dan penilaian taraf keseriusan kesalahan itu.

Dalam belajar bahasa setiap orang pasti pernah melakukan kesalahan. Tarigan (1988) mengatakan bahwa kesalahan merupakan sisi yang mempunyai cacat pada ucapan dan tulisan pembelajar, sedangkan James (1998) mengatakan bahwa kesalahan berbahasa adalah kegagalan dalam menggunakan suatu bahasa. Corder (1981) membedakan pengertian penyimpangan pemakaian bahasa berdasarkan sebab-sebabnya, yaitu mistakes (silap), lapses (selip) dan error 
(salah). Mistakes adalah penyimpangan pemakaian bahasa yang terjadi karena penutur tidak mampu menentukan ungkapan secara tepat sesuai dengan situasi yang ada. Lapses adalah penyimpangan pemakaian bahasa yang terjadi karena beralihnya pusat perhatian pada topik pembicaraan. Dan Error yaitu penyimpangan pemakaian bahasa dari struktur baku karena pembelajar belum menguasai sepenuhnya kaidah bahasa. Kesalahan (error) disebabkan oleh faktor kompetensi, maksudnya pembelajar belum menggunakan sistem bahasa yang ada. Kesalahan biasanya terjadi secara konsisten dan sistematis

Dalam menganalisis kesalahan. Analisis kontrastif digunakan untuk menginterpretasikan penyebab kesalahan. Tarigan (1988) berpendapat bahwa analisis kostrastif adalah prosedur kerja atau kegiatan membandingkan stuktur B1 dengan B2 untuk mengidentifikasi perbedaan diantara kedua bahasa. Dalam hal ini yang dibandingkan adalah struktur B1 yaitu bahasa Indonesia dengan B2 yaitu bahasa Jepang. Adanya persamaan antara B1 dengan B2 mengisyaratkan kemudahan belajar bahasa, sedangkan perbedaan antara B1 dengan B2 akan membuat pembelajar kesulitan belajar bahasa.

\subsection{Objek Penelitian}

Objek penelitian ini adalah untuk mendeskripsikan kesalahan gramatikal dan kesalahan leksikal pada bahasa tulis perawat STIKES Medistra Lubuk Pakam sebagai peserta magang ke Jepang. STIKES Medistra Lubuk Pakam merupakan tempat penulis melaksanakan pengabdian masyarakat yang didanai LPPM Universitas Sumatera Utara tahun 2019.

\section{METODE PELAKSANAAN}

Penelitian ini menggunakan metode kuantitatif Brown dan Rodgers (2002). Metode kuantitatif untuk menganalisis kesalahan dan mendeskripsikan bentuk-bentuk kesalahan untuk analisis kualitatif.

\section{HASIL DAN PEMBAHASAN}

3.1 Persentase Jumlah Kesalahan Gramatikal dan Kesalahan Leksikal

Hasil analisis data terdapat 120 kesalahan yang dilakukan perawat Medistra Lubuk Pakam. Adapun jenis kesalahan yang dibuat perawat berdasarkan taksonomi linguistik meliputi kesalahan dibidang morfologi,sintaksis dan kesalahan dibidang leksikal. Kesalahan morfologi dan kesalahan sintaksis dikategorikan ke dalam kesalahan gramatikal. Secara rinci persentase kesalahan yang dibuat oleh perawat dalam bidang morfologi, sintaksis, dan kesalahan leksikal adalah sebagai berikut:

\begin{tabular}{clcc}
\hline NO & JENIS KESALAHAN & JUMLAH & PERSENTASE \\
\hline $\mathbf{1}$ & Kesalahan dibidang morfologi & 28 & $23,38 \%$ \\
$\mathbf{2}$ & Kesalahan dibidang sintaksis & 40 & $33,66 \%$ \\
$\mathbf{3}$ & Kesalahan dibidang leksikal & 52 & $42,96 \%$ \\
& Jumlah & 120 & $100 \%$
\end{tabular}

Tabel 3.1.1. Jenis dan persentase jumlah kesalahan yang dilakukan oleh perawat berdasarkan taksonomi linguistik.

Dari data di atas jelas terlihat bahwa jenis kesalahan yang paling banyak dibuat oleh perawat adalah kesalahan dibidang leksikal sebanyak 42,96 \%, kemudian kesalahan sintaksis sebanyak $33.66 \%$ dan yang paling sedikit adalah kesalahan morfologi yakni sebanyak 23,38\%. 
Dibidang morfologi terdapat 28 kesalahan yang paling banyak dilakukan oleh perawat adalah kesalahan penghilangan penanda verba kala lalu 33,49\% dan 42,19\% penggunaan penanda verba pasif, kemudian diikuti oleh kesalahan penggunaan kata ulang 20,19\% dan yang paling sedikit adalah kesalahan penggunaan morfem berubah yakni sebanyak 4,13\%. Untuk lebih jelas dapat dilihat pada tabel dibawah ini

\begin{tabular}{clcc}
\hline NO & \multicolumn{1}{c}{$\begin{array}{c}\text { KESALAHAN } \\
\text { MORFOLOGI }\end{array}$} & JUMLAH & PERSENTASE \\
\hline $\mathbf{1}$ & $\begin{array}{l}\text { Penghilangan penanda verba } \\
\text { kala lalu }\end{array}$ & 9 & $33,49 \%$ \\
$\mathbf{2}$ & $\begin{array}{l}\text { Penggunaan penanda verba } \\
\text { bentuk pasif }\end{array}$ & 12 & $42,19 \%$ \\
$\mathbf{3}$ & Penggunaan kata ulang & 6 & $20,19 \%$ \\
$\mathbf{4}$ & Penggunaan morfem berubah & 1 & $4,13 \%$ \\
& Jumlah & 28 & $100 \%$ \\
\hline
\end{tabular}

Tabel 3.1.2. Jenis dan persentase jumlah kesalahan dibidang morfologi

Kesalahan yang paling sering dilakukan oleh perawat dibidang sintaksis adalah kesalahan struktur frasa sebanyak 38,2 \%, kesalahan struktur kalimat 24,2\%, dan kesalahan penggunaan partikel sebanyak $37,6 \%$,. Untuk lengkapnya perhatikan tabel berikut ini:

\begin{tabular}{clcc}
\hline NO & KESALAHAN SINTAKSIS & JUMLAH & PERSENTASE \\
\hline $\mathbf{1}$ & Struktur frasa & 15 & $38,2 \%$ \\
$\mathbf{2}$ & Struktur kalimat & 10 & $24,2 \%$ \\
$\mathbf{3}$ & Penggunaan dan penghilangan & 25 & $37,6 \%$ \\
& partikel & & \\
$\quad$ Jumlah & 40 & $100 \%$ \\
\hline
\end{tabular}

Tabel 3.1.3. Jenis dan persentase jumlah kesalahan dibidang sintaksis.

Kesalahan dibidang leksikal mencakup kesalahan pemilihan kata yang tidak tepat sebanyak 46,58 \%, kesalahan penggunaan kata bilangan sebanyak 33,23\% dan kesalahan penggunaan kata sapaan sebanyak 20,19\% seperti tabel berikut ini:

\begin{tabular}{clcc}
\hline NO & KESALAHAN LEKSIKAL & JUMLAH & PERSENTASE \\
\hline $\mathbf{1}$ & Penggunaan kata yang tidak tepat & 24 & $46,58 \%$ \\
$\mathbf{2}$ & Penggunaan kata bilangan & 17 & $33,23 \%$ \\
$\mathbf{3}$ & Penggunaan kata sapaan & 11 & $20,19 \%$ \\
& Jumlah & 52 & $100 \%$ \\
\hline
\end{tabular}

Tabel 3.1.4. Jenis dan persentase jumlah kesalahan leksikal.

\subsection{Kesalahan Bidang Morfologi}

Kesalahan dibidang morfologi yang dibuat oleh perawat peserta magang ke Jepang meliputi penghilangan penanda verba kala lalu, penghilangan penanda verba pasif, kata ulang dan morfem berubah.

a) Kesalahan Penanda Verba Kala Lalu

Contoh : watashi wa mou Jakarta e ikimasu. Seharusnya 'watashi wa mou Jakarta $e$ ikimashita' 'saya sudah pergi ke Jakarta'. Penanda verba kala lalu adalah /-mashital, perawat membuat kesalahan karena dipengaruhi kata /mou/ artinya'sudah' sehingga tidak menggunakan penanda/-mashita/ sebagai tanda verba kala lalu. Watashi 'saya'wa 'penanda 
subjek'mou'sudah' Jakarta e'penanda tujuan'ikimashita'pergi'. /ik-/ morfem dasar /-mashita/ penanda verba kala lalu.

b) Kesalahan Penggunaan Penanda Verba Bentuk Pasif.

Contoh : 1. Rina san ni ryoushin ga okane wo okuraremashita. Seharusnya 'Rina san ni ryoushin ga okane wo okurimashita' 'Rina dikirimi uang oleh orang tuanya'. Perawat membuat kesalahan dengan menggunakan terjemahan literal pada kata /dikirimi/, sehingga menggunakan verba pasif bahasa Jepang. Verba pasif bahasa Jepang ditandai/-raremasu/ yang sangat diyakini pembelajar bahasa Jepang merupakan verba berawalan /di-/ dalam bahasa Indonesia. Perawat salah memindahkan karena kaidah bahasa Indonesia verba transitif dapat dibentuk menjadi verba pasif yang berawalan /di-/. Namun sebenarnya tidak semua verba berawalan /di-/merupakan verba pasif bahasa Jepang.Tanaka (1991) menjelaskan bahwa verba pasif bahasa Jepang dapat digunakan untuk verba berawalan /di-/ bahasa Indonesia, namun tidak dapat begitu saja, karena ada beberapa hal yang harus diperhatikan seperti ; apakah objek atau benda yang dikenai perbuatan adalah benda hidup atau bukan benda hidup.

Contoh : 'Rina san wo tomodachi ga machimashita 'Rina san wo'Rina' tomodachi ga'teman' machimashita 'ditunggu'. Perawat membuat kesalahan dengan verba pasif /mataremashita/.

c) Kesalahan Penggunaan Kata Ulang.

Contoh : 1. /Shima-shima/ 'pulau-pulau' seharusnya /shima-zimal

2./hito-hito/ 'orang-orang' seharusnya /hito-bito/

Perawat membuat kesalahan dengan memindahkan langsung kaidah kata ulang bahasa Indonesia ke dalam bahasa Jepang.

d) Kesalahan Penggunaan Morfem Berubah

Contoh :

1. /hachi sen/ 'delapan ribu' seharusnya/hassen/. /hachil akan berubah bunyi apabila melekat dengan morfem lain.

2. Ihon hako/ 'kotak buku' seharusnya /honbako/. Morfem /hako/ akan berubah bunyi apabila melekat dengan morfem lain.

e) Kesalahan dibidang Sintaksis

1. Kesalahan Struktur Frasa

Contoh : 1. Ichiban shima ue 'pulau paling atas' seharusnya ichiban ue ni aru shima.

2. hana lavender 'bunga lavender' seharusnya lavender no hana.

3. sensei nihon go 'guru bahasa Jepang' seharusnya nihon go no sensei.

2. Kesalahan Struktur Kalimat

Contoh : 1. Sumimasen, konnichiwa, mina san 'maaf, selamat siang semuanya' seharusnya mina san, konnichiwa.

2. Nihon ni chikai umi 'Jepang dekat laut' seharusnya nihon wa umi ni chikai.

3. kono hen ni takusan mise no tabemono ga arimasu 'disekitar sini banyak toko makanan' seharusnya kono hen ni tabemono no mise ga takusan arimasu.

3. Kesalahan Penggunaan dan Penghilangan Partikel.

Contoh :

1. Asa hachi ji ni uchi dete, byouin e ikimasu. 'keluar rumah jam 8 pagi, dan pergi ke rumah sakit' seharusnya asa hachi ji ni uchi wo dete...., perawat menhilangkan partikel wo pada kata $u$ chi.

2. Oisha san wa heya de imasu 'dokter ada di ruangan' seharusnya oisha san wa heya ni imasu. Perawat mempertukarkan partikel $n i$ dan de, karena kedua tersebut bermakna preposisi di. 
3. Watashi tachi wa mainichi basu de notte, byouin e ikimasu ' kami setiap hari pergi ke rumah sakit naik bus' seharusnya ........basu ni notte,...Perawat membuat kesalahan menggunakan partikel de pada kata notte yang bermakna naik, seharusnya ...basu ni notte atau basu de itte 'naik bus'.

f) Kesalahan dibidang Leksikal.

1. Kesalahan Penggunaan Leksikal Nomina

Contoh: Hana no kouen 'taman bunga'. Perawat membuat kesalahan dengan menambahkan kata hana 'bunga'. Kouen artinya taman bunga, jadi tidak perlu menambah kata hana 'bunga'.

2. Kesalahan Penggunaan Leksikal Verba

Contoh :

a. Denki ga shinimashita 'listrik mati, seharusnya teiden. Perawat membuat kesalahan dengan menggunakan kata shinimashita yang bermakna mati untuk mahluk hidup.

b. b.kusuri wo tabemashita 'makan obat' seharusnya kusuri wo nomimashita.'minum obat.

c. megane wo tsukatte imasu 'memakai kaca mata' seharusnya megane wo kakete imasu. Perawat menggunakan kata tsukatte imasu yang bermakna memakai. Dalam bahasa Jepang verba memakai ada beberapa bentuk yaitu fuku wo kite imasu 'memakai baju', boshi wo kabutte imasu 'memakai topi', kutsu wo haite imasu 'memakai sepatu'.

3. Kesalahan Penggunaan Leksikal Adjektiva

Contoh :

a. Yamada san wa utsukushii desu. 'nona Yamada cantik'. Seharusnya Yamada san wa kirei desu. Kata utsukushi dan kirei bermakna cantik, tetapi utsukushii 'cantik'tidak digunakan untuk manusia.

b. Watashi wa chiisai okane ga arimasen. 'saya tidak punya uang receh' seharusnya watashi wa komakai okane ga arimasen. Perawat membuat kesalahan dengan memindahkan langsung bahasa Indonesia kata uang kecil menjadi chiisai okane.

c. Watashi no imouto wa shogakusei desu.'adik perempuan saya pelajar SD' seharusnya imouto wa shogakusei desu.Kata imouto bermakna adek perempuan saya. Perawat menambahkan pronomina watashi 'saya'. Bentuk ini tidak logis dalam bahasa Jepang.

d. Oisha san, watashi wa kaze wo hiite, mite mo ii desu ka. 'Dokter, saya masuk angin, boleh tolong diperiksa' Oisha san artinya dokter, tetapi kata sapaan untuk dokter adalah sensei. Perawat memindahkan kata sapaan dokter bahasa Indonesia kedalam bahasa Jepang.

\section{KESIMPULAN}

Adanya perbedaan struktur bahasa Jepang dan bahasa Indonesia membuat perawat STIKES Medistra Lubuk Pakam sebagai peserta magang ke Jepang mengalami kesulitan ketika membuat bahasa Jepang tulis. Perawat cenderung memindahkan sistem gramatikal dan leksikal B1 (bahasa Indonesia) kedalam bahasa Jepang. Karena interferensi merupakan fenomena bahasa yang timbul akibat kontak bahasa, menyebabkan penggunaan stuktur dan leksikal bahasa Indonesia menyusup ke dalam bahasa Jepang tulis perawat, sehingga menimbulkan kesalahan. Oleh karena itu sebagai implikasi pedagogis, bahan atau materi pengajaran bahasa Jepang dapat menfaatkan analisis kontrastif untuk mengurangi interferensi.

Adapun kesalahan berdasarkan taksonomi linguistik yang dibuat perawat STIKES Medistra Lubuk Pakam sebagai peserta magang ke Jepang dalam 45 bahasa tulis adalah kesalahan dibidang 
morfologi sebanyak 23,38\% (28 buah), dibidang sintaksis sebanyak 33,66\% (40 buah) dan kesalahan dibidang leksikal sebanyak 42,96\% (52 buah).

\section{UCAPAN TERIMAKASIH}

Penulis mengucapkan terima kasih kepada Rektor Universitas Sumatera Utara Prof.Dr.Runtung Sitepu, M.Hum, Ketua LPPM-USU Prof.Dr.Tulus Vor.Dipl.Math.M.Si, Ph.D, Sekretaris LPPMUSU Prof,Dr. Irna Marsaulina, yang telah memberi dana pengabdian kepada masyarakat tahun 2019.

\section{DAFTAR PUSTAKA}

Arfianty, Rani\&Hasibuan Adriana. 1997. Composition In The Japanese Error Analysis Of Sentence Essay, International Journal Of Multidiciplinary Research and Development. 5 (1), 6-10.

Brown, J.D\&Rodgers, T.S. 2002. Doing Second Language Use. Cambridge Centre. USA : Blackwell.td.

Corder,S,Pit. 1973. Introducing Applied Linguistics. Pinguin Books. Ltd. USA.

--... 1988. Strategies Of Communication. New York. Longman Group.Limited.

Ellis. Rod. 2015. Understanding Second Language Acquisition. UK : Oxford University Press.

Gass, S,M.\&Selinker,L.2008. Second Language Acquisition, An Introductory Course. New York: Routledge.

Tarigan, H.G. 1988. Pengajaran Pemerolehan Bahasa. Bandung. Angkasa. 1995 Pengajaran Analisis Kesalahan Berbahasa. Bandung Angkasa.

Yoshikawa, Taketoki. 1997. Nihon Go Goyou Bunseki; Japanese Error Analysis. Japan. Meiji Shoin.

Weinreich, U.1970. Language In Contact, Findings And Problems. Linguistics Circle. Moution Publishers. New York. 